\title{
Phytochemical Compounds in Arundo donax L. Rhizome and Antimicrobial Activities
}

\author{
Kanoktip Pansuksan ${ }^{1, *}$, Sophida Sukprasert ${ }^{1,2}$, Netiya Karaket ${ }^{3, *}$
}

Kanoktip Pansuksan ${ }^{1, *}$, Sophida Sukprasert ${ }^{1,2}$, Netiya Karaket ${ }^{3, *}$

${ }^{1}$ Chulabhorn International College of Medicine, Thammasat University, 99, Phaholyothin Rd., Khlong 1 Sub District, Khlong Luang District, Pathumthani 12120, THAILAND.

${ }^{2}$ Protein and Proteomics Research Center for Commercial and Industrial Purposes (ProCCl), Khonkaen University, Khonkaen, 40002, THAILAND.

${ }^{3}$ School of Interdisciplinary Studies, Mahidol University Kanchanaburi Campus, 199 Sangchuto Rd., Saiyok, Kanchanaburi, 71150 THAILAND.

\section{Correspondence}

\section{Kanoktip Pansuksan}

Chulabhorn International College of

Medicine, Thammasat University, 99

Phaholyothin Rd., Khlong 1 Sub District,

Khlong Luang District, Pathumthani 12120 ,

THAILAND.

E-mail: kanoktip@staff.tu.ac.th

\section{Netiya Karaket}

School of Interdisciplinary Studies, Mahido

University Kanchanaburi Campus, 199

Sangchuto Rd., Saiyok, Kanchanaburi,

71150, THAILAND.

E-mail: netiya.kar@mahidol.ac.th

History

- Submission Date: 21-12-2019:

- Review completed: 06-01-2020;

- Accepted Date: 22-01-2020.

DOI : 10.5530/pj.2020.12.45

Article Available online

http://www.phcogj.com/v12/i2

\section{Copyright}

(C) 2020 Phcogi.Com. This is an openaccess article distributed under the terms of the Creative Commons Attribution 4.0 International license.

\section{ABSTRACT}

Introduction: The aerial part of Arundo donax L., giant reed, is a well-known fuel source used in many countries. Methods: Phytochemical compounds in A. donax L. rhizome, sequentially extracted with hexane (HEX), dichloromethane (DCM), ethyl acetate (EA), and methanol $(\mathrm{MeOH})$, were identified using gas chromatography-mass spectrometry. Antimicrobial activities of the rhizome extracts were evaluated using disc diffusion assay against yeast (Candida albicans), and bacteria Gram-positive (Staphylococcus aureus ATCC 25923, Bacillus cereus ATCC11778, and Bacillus subtilis ATCC6633) and Gram-negative (Escherichia coliATCC25922). Results: The detected phytochemicals were screened against WILEY07 library; 84 compounds matched with a similarity $\geq 90 \%$. All the characterized compounds were grouped based on their functional group. The major phytochemicals in the HEX, DCM, and EA extracts belonged to sterol groups, while lipids, fatty acids, and related conjugates were the main components of the methanolic extract. The other characterized compounds were hydrocarbons, phenolics, terpenoids, xanthones, and xanthene. Growth of $B$. subtilis was inhibited by the HEX, DCM, $\mathrm{EA}$, and $\mathrm{MeOH}$ extracts, whereas $B$. cereus growth was inhibited only by the DCM and EA extracts. However, growth of $E$. coli and $C$. albicans could be not inhibited by $A$. donax L. rhizome extracts. Analysis of the compounds as well as their antibacterial activities via hierarchical clustering showed that hexadecanoic acid is the major compound influencing $B$. subtilis growth, while, $B$. cereus growth was affected by xanthone. Conclusions: Rhizomes of $A$. donax $\mathrm{L}$. is one potential source of antimicrobial agents and further applied in medicinal uses.

Key words: Giant reed, Bacteria, GC-MS, HCA.

\section{INTRODUCTION}

Arundo donax L. (Poaceae) is a giant reed like grass with versatile economic (biofuel) and biomedical uses. The rhizome of this plant grows horizontally underground and has a storage function which has been the source material for pharmaceutical and biomedical utilizations. Acidic and neutral/ alkaline fractions have been reported to inhibit Prymnesium parvum, ichthyotoxic golden alga. ${ }^{1}$ In addition, traditional medicine has used $A$. donax $\mathrm{L}$. as an emollient and a diuretic agent. ${ }^{2,3}$ Furthermore, basic biomedical research has used the rhizome from which purified n-acetyl-D-glucosamine was obtained. This phytochemical compound has been reported to exhibit anti-proliferation activity against a human cancer cell line. ${ }^{4}$

In view of these biomedical uses, investigation of phytochemical compounds in A. donax L. is a warranted procedure in order to establish the knowledge needed to further exploit this plant for pharmaceutical uses. A number of phytochemical compounds from A. donax L. have been extracted using various procedures as well as isolated/ identified using chromatographic techniques. For example, n-acetyl-D-glucosamine, a specific lectin, has been isolated from $A$. donax $\mathrm{L}$. rhizomes using affinity chromatography. ${ }^{4}$ The phytochemical compounds of $A$. donax stems were extracted with acetone and re-dissolved in chloroform before fractionation. ${ }^{5}$ The analysis of stem extract by gas chromatography (GC) and gas chromatography-mass spectrometry (GC-MS) revealed compounds such as long-chain $\mathrm{n}$-fatty acids, n-alkanes, $\mathrm{n}$-aldehydes, n-alcohols, monoglycerides, free and esterified sterols, and terpenols. Recently, the non-structural carbohydrates in A. donax $\mathrm{L}$. were identified and the results revealed that the contents affected the dry matter and water extracts, which further caused the differences in their biomass. ${ }^{6}$ However, the identification of phytochemical compounds in $A$. donax $\mathrm{L}$. is still unclear with concerning to their types and contents. Therefore, in this study, the $A$. donax L. rhizomes extracted with various solvents were phytochemically characterized including the antimicrobial activities of their metabolites.

\section{MATERIALS AND METHODS}

\section{Plant materials and extraction}

Whole plants of $A$. donax $\mathrm{L}$. during the flowering stage were collected in Thailand. The voucher specimen was prepared by Forest Herbarium (BKF) Department of National Parks, Wildlife and Plant Conservation, Ministry of Natural Resources and Environment to use as plant reference (Reference number: BKF NO. 19581). The voucher specimen compared with that in BKF database was identified as A. donax L. by Mr. Sukid Rueangruea, Forestier Professional Academician of BKF. A. donax L. 
rhizomes were dried at $50^{\circ} \mathrm{C}$ before pulverizing. Sequential extraction based on the polarity index of various solvents used hexane (HEX), dichloromethane (DCM), ethyl acetate (EA), and methanol $(\mathrm{MeOH})$, respectively. The rhizome was initially extracted by immersing 1 -g powder with $10 \mathrm{ml} \mathrm{HEX}$, followed by $15 \mathrm{~min}$ of sonication, then overnight maceration. Consequently, the residues were removed from the HEX extract by filtration through a membrane paper (Whatman ${ }^{\circ}$ no. 1). The residue was consecutively extracted with DCM, EA, and $\mathrm{MeOH}$, respectively. Then, the solvents were removed from all the extracts by vacuum evaporation, and the extracts were stored at $-20^{\circ} \mathrm{C}$ for subsequent antimicrobial activity test and phytochemical analysis by GC-MS.

\section{GC-MS analysis}

GC-MS was used to characterize the phytochemical compounds which were dissolved in their extracted solvents for a final concentration of 10 $\mathrm{mg} / \mathrm{ml}$. Methyl heptadecanoate was used as an internal standard. The extracts were analyzed using an HP5-MS capillary-fused silica column (30 m length, $0.25 \mathrm{~mm}$ I.D., and $0.25 \mathrm{~m}$ film thickness), helium as a carrier gas at a flow rate of $1 \mathrm{ml} / \mathrm{min}$, and $250^{\circ} \mathrm{C}$ injector temperature in splitless mode. The oven temperature condition was as follow; $40^{\circ} \mathrm{C}$ initiation, increasing $4^{\circ} \mathrm{C} / \mathrm{min}$ to $300^{\circ} \mathrm{C} / \mathrm{min}$ and increasing $5^{\circ} \mathrm{C} / \mathrm{min}$ to $320^{\circ} \mathrm{C} / \mathrm{min}$ for $10 \mathrm{~min}$. The mass range of analyzed compounds detected at $\mathrm{m} / z$ 30-500 amu. ${ }^{7}$ Screening against the WILEY07 library enabled characterization of the phytochemical compounds from A. donax L., with similarity of at least $90 \%$ warranting further analysis.

\section{Antimicrobial activity assay}

The antimicrobial activities assay was performed by the disc diffusion method $^{8}$ against yeast $C$. albicans and two types of bacteria: 1) Grampositive (S. aureus ATCC 25923, B. cereus ATCC11778, and B. subtilis ATCC6633) and 2) Gram-negative (E. coli ATCC25922). Bacteria were cultured in Luria-Bertani broth at $37^{\circ} \mathrm{C}$ for $16-18 \mathrm{~h}$; the broth was replaced with fresh Luria-Bertani broth and the culture continued for 2-3 h. C. albicans was cultured in yeast extract peptone dextrose (YPD) liquid medium at $30^{\circ} \mathrm{C}$ for $16-18 \mathrm{~h}$; the medium was replaced with fresh YPD medium and the culture continued for 2-3 h. Each microbial inoculum was diluted in Mueller-Hinton $(\mathrm{MH})$ broth to obtain 0.1 $\mathrm{OD}_{600}$. Then, the pour plate technique was performed by mixing $1 \mathrm{ml}$ of all microbial inocula with $9 \mathrm{ml}$ of $\mathrm{MH}$ agar. All extracts were prepared by dissolving in $100 \%$ dimethyl sulfoxide at a concentration $100 \mu \mathrm{g} /$ $\mu \mathrm{l}$. The extracts (calculated as $2 \mathrm{mg} /$ disc) were dropped on paper discs sized $6 \mathrm{~mm}$ in diameter and allowed to dry in a laminar flow cabinet; $100 \%$ dimethyl sulfoxide was used as a control. The discs with extracts were placed on microbial plates before overnight co-incubation at $37^{\circ} \mathrm{C}$ for all tested bacteria, and $30^{\circ} \mathrm{C}$ for C. albicans. Growth inhibition was detected measuring the clear zone.

\section{Hierarchical clustering analysis (HCA)}

The extracted phytochemical compounds with similarity values $\geq$ $90 \%$ and antimicrobial activity (only inhibited microbial strains) were grouped using HCA as previously reported by Sumner et al. (2003). ${ }^{9}$ The overall dataset was visually analyzed and defined by multiexperiment viewer $(\mathrm{MeV})$, as Pearson correlation, using average linkage clustering. ${ }^{10}$ The relationship between detected compounds and antimicrobial activity was presented as a heat map pattern with the degree of difference indicated in a representative color.

\section{RESULTS AND DISCUSSION}

\section{Phytochemical compounds in A. donax L. extract detected by GC-MS}

Dried rhizomes were sequentially extracted with HEX, DCM, EA, and $\mathrm{MeOH}$, respectively, as described in the experimental section.
All the four extracts were stored at $-20^{\circ} \mathrm{C}$ before to analysis of the phytochemical compounds by GC-MS. The compounds were screened against the WILEY07 library; 84 phytochemicals were identified and the compounds with a matching-similarity $\geq 95 \%$ were presented in Table 1.

Methyl heptadecanoate was used as the internal standard for comparing the phytochemical contents in different extracts. Nineteen identical compounds were detected in the HEX extract, such as 2-benzoxazolone and heptadecane, which were not found in the other extracts. Five, 11, and seven specific compounds were detected only in DCM, EA, and $\mathrm{MeOH}$ extracts, respectively. Interestingly, two compounds, phenol, 3,5-bis(1,1-dimethylethyl)- and hexadecanoic acid (or palmitic acid), were detected in all the extracts. The most diverse identified compounds (49 compounds) were detected in the HEX extract, whereas fewer compounds were detected in the DCM (38 compounds), EA (34 compounds), and $\mathrm{MeOH}$ extracts (18 compounds). Use of various solvents for extraction resulted in different contents and types of compounds.

All detected phytochemicals in each extract were grouped, as shown in Figure 1, based on their functional groups as follows 1) lipids, fatty acid and conjugates 2) hydrocarbons 3) phenolic compounds 4) sterols 5) terpenoids 6) xanthones and xanthenes, and 7) other compounds.

The phytochemical compounds in A. donax L. stems analyzed by GCMS revealed that long-chain fatty acids, alkanes, aldehydes, alcohols, ketones, sterols and conjugates, terpenoids, monoglycerides, and glucosides were the major constituents in stem fibres. ${ }^{5}$ However, in this study, sterols were found to be the major constituents of the HEX, DCM, and EA extracts from A. donax L. with $52 \%, 42 \%$, and $30 \%$ relative content, respectively. Although sterol was found in methanolic

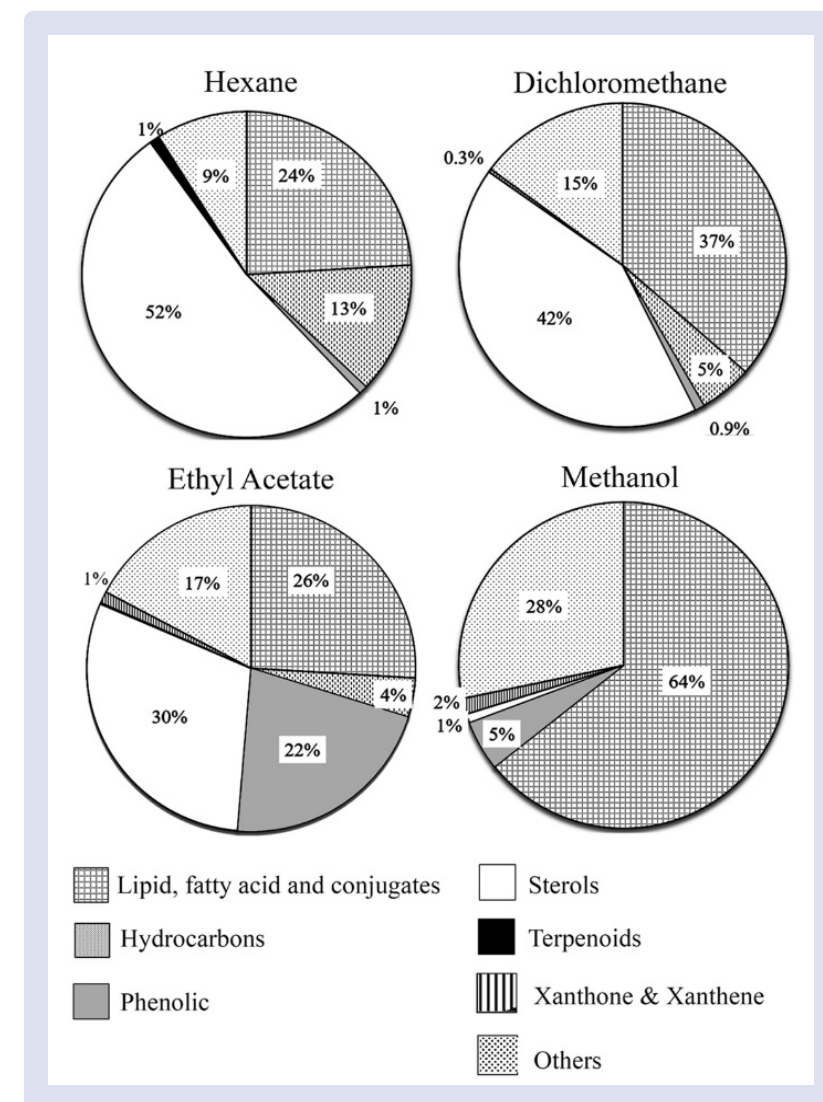

Figure 1: Phytochemical compounds (\% proportion) detected in hexane, dichloromethane, ethyl acetate, and methanolic extracts of $A$. donax L. rhizomes. 
Table 1: Phytochemical constituents in A. donax L. rhizome extracts characterized by screening against WILEY07 library after analysis by GC-MS.

\begin{tabular}{|c|c|c|c|c|c|c|}
\hline \multirow{2}{*}{$\frac{\mathrm{RT}}{(\mathrm{min})}$} & \multirow[t]{2}{*}{ Compound name } & \multirow{2}{*}{$\begin{array}{c}\text { Match } \\
\text { Similarity }\end{array}$} & \multicolumn{4}{|c|}{ Relative content (\%) } \\
\hline & & & Hex & DCM & EA & $\mathrm{MeOH}$ \\
\hline 7.43 & 2,3-Butanediol (CAS) Butane-2,3-diol & 96 & - & - & 31.07 & - \\
\hline 7.44 & Heptane, 2,4-dimethyl- & 97 & 2.48 & 3.78 & - & - \\
\hline 15.57 & Octane, 5-ethyl-2-methyl- & 95 & 7.64 & 9.88 & - & - \\
\hline 15.69 & Undecane, 3,7-dimethyl- & 95 & - & - & 0.81 & - \\
\hline 17.07 & Phenol, 2-methoxy- & 98 & - & - & 4.67 & 1.30 \\
\hline 17.28 & Decane, 3,7-dimethyl- & 96 & 2.12 & - & - & - \\
\hline 20.67 & 1-Dodecene & 98 & 1.41 & - & 1.44 & - \\
\hline 23.31 & Undecane, 4-ethyl- & 95 & 1.60 & 1.51 & - & - \\
\hline 23.90 & Tetradecane & 95 & 9.36 & 8.82 & 1.10 & - \\
\hline 24.40 & Dodecane, 4,6-dimethyl- & 96 & 0.99 & - & - & - \\
\hline 27.77 & 1-Pentadecene & 97 & 0.59 & 2.52 & - & - \\
\hline 31.00 & Undecane, 3,8-dimethyl- & 95 & 2.85 & - & - & - \\
\hline 33.76 & 2(3H)-Benzoxazolone (CAS) 2-Benzoxazolone & 95 & 90.95 & - & - & - \\
\hline 34.20 & 1-Hexadecene & 97 & 5.57 & - & - & - \\
\hline 36.36 & 9H-Xanthene & 95 & - & - & 3.94 & 1.44 \\
\hline 39.92 & 3-Eicosene, (E)- & 96 & - & - & 4.88 & - \\
\hline 41.89 & 9-Octadecenoic acid (Z)- & 97 & - & 9.07 & - & - \\
\hline 42.21 & Xanthone & 96 & - & 4.25 & 2.50 & 0.52 \\
\hline 44.68 & Hexadecanoic acid & 96 & 32.80 & 108.97 & 50.08 & 27.65 \\
\hline 45.11 & 1-Docosene & 97 & 5.67 & - & - & - \\
\hline 45.98 & Heptadecanoic acid, methyl ester & 96 & 100.00 & 100.00 & 100.00 & 100.00 \\
\hline 47.34 & n-Heptadecanol-1 & 96 & 1.25 & - & - & - \\
\hline 47.58 & octadeca-9,12-dienoic acid methyl ester & 96 & - & 1.55 & 1.72 & 0.93 \\
\hline 48.28 & Octadecanoic acid, methyl ester & 95 & 0.64 & - & - & - \\
\hline 48.73 & 9,12-Octadecadienoic acid (Z,Z)- & 95 & - & 201.95 & 42.87 & 40.58 \\
\hline 49.13 & 1-Octadecyne & 96 & 6.25 & - & 5.59 & - \\
\hline 53.26 & Tetratetracontane & 97 & 4.13 & 3.80 & - & - \\
\hline 54.22 & Tetracosane & 98 & 5.55 & 4.77 & - & - \\
\hline 54.54 & Pentadecanoic acid, 2-hydroxy-1-(hydroxymethyl)ethyl ester & 97 & 4.10 & - & 2.10 & - \\
\hline 56.59 & Hexadecanoic acid, 2-hydroxy-1-(hydroxymethyl)ethyl ester & 97 & 10.52 & 46.50 & 16.83 & - \\
\hline 57.36 & Di-n-octyl phthalate & 96 & - & - & - & 0.95 \\
\hline 58.16 & 1-TRICOSENE & 96 & - & - & 0.70 & - \\
\hline 60.11 & Tetratriacontane & 96 & 43.07 & 5.35 & - & - \\
\hline 63.67 & Heneicosane & 97 & 29.12 & 7.65 & - & - \\
\hline 66.93 & Nonacosane & 96 & - & 6.36 & - & - \\
\hline 70.19 & $\begin{array}{c}\text { Stigmasta-5,22-dien-3-ol, (3.beta.,22E)- } \\
\text { ( } \beta \text {-Stigmasterol) }\end{array}$ & 96 & 142.86 & 111.12 & 25.81 & - \\
\hline 71.30 & $\begin{array}{c}\text { Stigmast-5-en-3-ol, (3.beta.,24S)- } \\
\text { ( } \beta \text {-Sitosterol) }\end{array}$ & 95 & 292.90 & 249.88 & 90.91 & - \\
\hline 71.54 & Tetratetracontane & 95 & 15.54 & - & - & - \\
\hline
\end{tabular}

RT: retention time; HEX: hexane extract; DCM: dichrloromethane extract; EA: ethyl acetate extract; $\mathrm{MeOH}$ : methanol extract.

extracts, it was not the main component (1\%). Lipids, fatty acids, and conjugates accounted for the majority of the methanolic extract, with a content of $64 \%$. The sterols or steroid alcohols, in A. donax L. included vitamin E, campesterol, 22,23-dihydrobrassicasterol, $\beta$-stigmasterol, $\beta$-sitosterol, and sitostenone. These sterols have been reported to have various activities, such as lowering plasma cholesterols, ${ }^{11}$ anticancer effects against skin carcinoma, ${ }^{12}$ and antidiabetic activities. ${ }^{13}$ Thus, $A$. donax L. rhizome maybe one important source of sterol compounds for further medicinal application. Phenolic compounds, such as phenol, 2-methoxy-; is another class that could be detected in all extracts; however, the EA extract presented the highest phenolic proportion at $21.5 \%$.

Hydrocarbons were detected in all extracts, except the $\mathrm{MeOH}$ extract. Since the electrons of hydrocarbons are equally shared by the adjacent atoms between the bonds, this compound group is better extracted by a non-polar solvent or a solvent with low polar index. Hydrocarbon compounds were detected in extracts derived from solvents with lower polarity index $\left(\mathrm{P}^{\prime}\right)$, such as $\operatorname{HEX}\left(\mathrm{P}^{\prime}=0.1\right), \mathrm{DCM}\left(\mathrm{P}^{\prime}=3.1\right)$, and EA $\left(\mathrm{P}^{\prime}=4.4\right)$, but not in the $\mathrm{MeOH}\left(\mathrm{P}^{\prime}=5.5\right)$ extract. ${ }^{14} \mathrm{~A}$ low proportion of the terpenoid squalene was detected in the HEX (1\%) and EA $(0.1 \%)$ extracts. Squalene, a precursor of sterol production, was reported to have antioxidant and immune-boosting, ${ }^{15}$ and protective activities against ultraviolet-induced skin cancer. ${ }^{16}$ In the root part of several plants, genes involved in secondary metabolite production might be expressed at a low level, as revealed by the low content of artemisinin, a terpenoid with antimalarial properties, in the root part of Artemisia annua. ${ }^{17}$ Xanthone and xanthene were detected in the DCM $(0.3 \%)$, EA (1\%), and $\mathrm{MeOH}(2 \%)$ extracts. Xanthone could be found in various plant organs, such as fruit peel (e.g. mangosteen pericarp), bark, or root. It exhibited anticancer, ${ }^{18-19}$ immune modulation, ${ }^{20}$ antioxidant, ${ }^{21}$ and antimicrobial activity. ${ }^{22}$ The analysis of $A$. donax $\mathrm{L}$. extracts in this study revealed that rhizomes are an important source of valuable phytochemical metabolites, which could have medicinal 
applications. All the four extracts were further analyzed for their effects on micro-organism growth, and the relationship between the detected phytochemicals and their anti-microbial activities was evaluated using HCA.

\section{HCA of detected metabolites in A. donax L. and their antimicrobial activities}

Antimicrobial activities of the four A. donax L. extracts including Hex, DCM, EA, and $\mathrm{MeOH}$ in crude forms were examined against the bacteria and yeast. Growth inhibition was determined based on clear zone after overnight co-incubation of the disc containing $2 \mathrm{mg}$ of each A. donax L. extract with bacteria and yeast. The results showed that all four extracts inhibited the growth of B. subtilis as presented in Table 2; the DCM extract showed the highest activity (18 $\mathrm{mm}$ of inhibition zone). The HEX, EA, and $\mathrm{MeOH}$ extracts showed no significant activity against $B$. subtilis ( $p \geq 0.01$ ). The growth of $B$. cereus, a human pathogenic bacterium, was inhibited by the DCM and EA extracts with $17.8 \mathrm{~mm}$ and $7.8 \mathrm{~mm}$ inhibition zone, respectively.

However, the HEX and $\mathrm{MeOH}$ extracts could not suppress its growth at this concentration. These results indicated that the DCM extract had the best antibacterial activity against the tested strains. Nevertheless, all four extracts could not inhibit E. coli, S. aureus, and C. albicans growth in this study. This first report proved that extraction of $A$. donax $\mathrm{L}$. using different solvents resulted in differences in antibacterial activities. Moreover, A. donax $\mathrm{L}$. has potential activities against $B$. subtilis and $B$. cereus. Since B. cereus is a Gram-positive human-pathogenic bacterium that causes foodborne diseases and some severe symptoms, such as vomiting and diarrhea, ${ }^{23}$ the antibacterial activity of $A$. donax L. extracts, especially DCM extract, indicates that $A$. donax $\mathrm{L}$. is a potential source of phytochemical compounds for antibiotic production.
Heat map visualization of antibacterial activities and relative phytochemical compounds was performed by HCA (Figure 2).

The results revealed that hexadecanoic acid had an important role in anti-B. subtilis activity as presented in the same cluster and pattern of heat map. Hexadecanoic acid, or palmitic acid, is a saturated fatty acid found in many organisms including plants. It was detected in all the extracts, with the DCM extract presenting the highest relative content (108.97\%), while the $\mathrm{MeOH}$ extracts showed the lowest at $27.65 \%$. This indicates that a higher hexadecanoic acid content would result in a higher anti-B. subtilis activity. In a further study, the anti- $B$. subtilis activity of $A$. donax $\mathrm{L}$. extract could be predicted from this fatty acid content. Isolated n-hexadecanoic acid from Canthium parviflorum leaves also showed antimicrobial activities against E. coli, S. aureus, B. subtilis, and C. albicans at dose 100 and $150 \mu \mathrm{g} .{ }^{24}$ According to the same pattern of expression in heat map, xanthone is the main compound which inhibited the growth of $B$. cereus. The DCM and EA extracts showed anti- $B$. cereus activities; xanthone was detected and identified in these two rhizome extracts with a content of $2.5-4.3 \%$. Xanthone is a tricyclic aromatic compound, which could be found in the $A$. donax L. stem. ${ }^{5}$ In addition to anticancer, immune modulation, and antioxidant activities, xanthones, the major active component derived from Calophyllum brasiliense Cambess. and Mammea americana L., showed antibacterial activities against $S$. aureus and E. coli. ${ }^{25}$ The dose used in this study ( $2 \mathrm{mg}$ extract/disc) was in the range similar to that used in previous studies, $1-2 \mathrm{mg} /$ disc for Andrographis paniculata, Morinda citrifolia, Piper sarmentosum, and Mitracarpus hirtus L. extracts; ${ }^{8,26,27}$ and $5 \mathrm{mg} /$ disc for A. annua extract. ${ }^{28}$ Further studies on the investigation of bioactivity of $A$. donax L. rhizomes should focus on these two active compounds.

Table 2: Antimicrobial activities of hexane, dichloromethane, ethyl acetate, and methanolic extracts in A. donax L. extracts by disc diffusion test.

\begin{tabular}{|c|c|c|c|c|}
\hline \multirow{2}{*}{ Tested microorganism } & \multicolumn{4}{|c|}{ Inhibition zone $(\mathrm{mm} .)^{1 /}$} \\
\hline & Hex & DCM & EA & $\mathrm{MeOH}$ \\
\hline B. subtilis & $6.3 \pm 5.5 \mathrm{~b}^{2 \ell}$ & $18.0 \pm 2.6 \mathrm{a}$ & $8.3 \pm 0.6 b$ & $5.2 \pm 4.5 \mathrm{~b}$ \\
\hline B. cereus & $0.0 \pm 0.0 c$ & $17.8 \pm 1.6 \mathrm{a}$ & $7.8 \pm 1.0 \mathrm{~b}$ & $0.0 \pm 0.0 c$ \\
\hline
\end{tabular}

HEX: hexane extract; DCM: dichrloromethane extract; EA: ethyl acetate extract; $\mathrm{MeOH}$ : methanol extract

${ }_{1}^{1}-$ The inhibition zones were presented in mean \pm SD with $6 \mathrm{~mm}$. diameter of tested disc.

2! The alphabet represented the significant statistical differences after analysis by ANOVA, Duncan's test with $p \leq 0.01$.

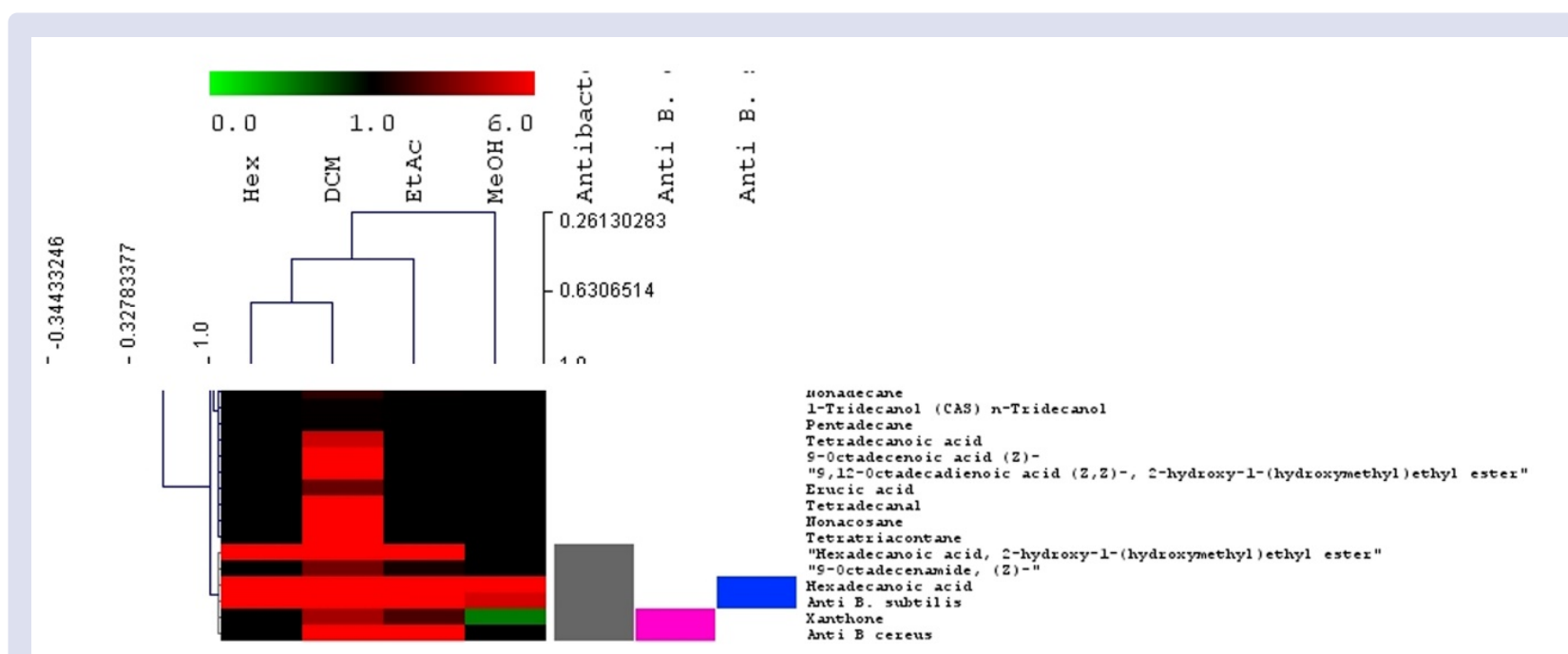

Figure 2: Heat map presented the relative different compounds of hexane (Hex), dichloromethane (DCM), ethyl acetate (EtAc), and methanolic $(\mathrm{MeOH})$ extracts of $A$. donax L. rhizomes and anti-B. cereus/B. subtilis activities analyzed by HCA. The horizontal color scale above the heat map was ranged from green (low content) to red (high content). The vertical pink and blue bar represented the detected compounds relating with anti-B. cereus and B. subtilis activity, respectively. 


\section{CONCLUSIONS}

The phytochemical compounds of $A$. donax L. extracted with HEX, DCM, EA, and $\mathrm{MeOH}$, were characterized by GC-MS in this study. Grouping of the detected compounds revealed diverse phytochemicals in both quantity and quality, of which sterols were the major component of the HEX, DCM, and EA extracts. Nevertheless, lipids, fatty acids, and conjugates were the main components of the $\mathrm{MeOH}$ extract. Moreover, based on antibacterial activity, we recommend using DCM for extracting the phytochemicals from A. donax $\mathrm{L}$. The study of A. donax L. rhizomes revealed that it has the potential to be used as a pharmaceutical source of phytochemical agents to treat diseases.

\section{ACKNOWLEDGEMENTS}

The authors gratefully acknowledge the financial support provided by Thammasat University under the TU New Research Scholar, Contract No. 21/2559. We gratefully acknowledge Prof. Dr. Sompong Klaynongsruang and Assoc. Prof. Dr. Sakda Daduang, Khon Kaen University, for their support of the microorganism used throughout this work. The authors thank to Mr. Wirapong Kantamala for bacterial preparation.

\section{CONFLICTS OF INTEREST}

None.

\section{REFERENCES}

1. Patiño R, Rashel RH, Rubio A, Longing S. Growth-suppressing and algicidal properties of an extract from Arundo donax, an invasive riparian plant, against Prymnesium parvum, an invasive harmful alga. Harmful Algae. 2018;71:1-9.

2. Miles DH, Tunsuwan K, Chittawong V, Hedin PA, Kokpol U, Ni CZ, et al. Agrochemical activity and isolation of $\mathrm{N}$ - (bromophenyl)-2,2- diphenylacetanilide from the Thai plant Arundo donax. J Nat Prod. 1993;56:1590-3.

3. Wassel GM, Ammar NM. Isolation of the alkaloids and evaluation of the diuretic activity of Arundo donax. Fitoterapia. 1984;55(6):357-8.

4. Kaur A, Singh J, Kamboj SS, Sexana AK, Shamugavel M. Isolation of an $\mathrm{N}$-acetyl-D-glucosamine specific lectin from the rhizomes of Arundo donax with antiproliferative activity. Phytochemistry. 2005;66(16):1933-40.

5. Coelho D, Marques G, Guti'errez G, Silvestre AJD, R'ı JCD. Chemical characterization of the lipophilic fraction of giant reed (Arundo donax) fibres used for pulp and paper manufacturing. Ind Crops Prod. 2007;26:229-36.

6. Proiettia S, Moscatelloa S, Fagnanob M, Fiorentinob N, Impagliazzob A, Battistellia A. Chemical composition and yield of rhizome biomass of Arundo donax L. grown for biorefinery in the Mediterranean environment. Biomass Bioenerg. 2017;107:191-7.

7. Karaket N, Wiyakruttab S, Lacaille-Duboisc MA, Supaibulwatana K. T-DNA Insertion Alters the Terpenoid Content Composition and Bioactivity of Transgenic Artemisia annua. Nat Prod Commun. 2014;9(3):363-6.

8. Pansuksan K, Sangthong R, Nakamura I, Mii M, Supaibulwatana K. Tetraploid induction of Mitracarpus hirtus $L$. by colchicine and its characterization including antibacterial activity. Plant Cell Tiss Organ Cult. 2014;117:381-91.

9. Sumner LW, Mendes P, Dixon RA. Plant metabolomics: large scale phytochemistry in the functional genomics era. Phytochemistry. 2003;62:81736.
10. Saeed Al, Sharov V, White J, Li J, Liang W, Bhagabati N, et al.TM4: a free, opensource system for microarray data management and analysis. Biotechniques. 2003;34(2):374-8

11. Amundsen $A L$, Ose L, Nenseter MS, Ntanios FY. Plant sterol ester-enriched spread lowers plasma total and LDL cholesterol in children with familial hypercholesterolemia. Am J Clin Nutr. 2002;76:338-44.

12. Ali H, Dixit S, Ali D, Alqahtani SM, Alkahtani S, Alarifi S. Isolation and evaluation of anticancer efficacy of stigmasterol in a mouse model of DMBA-induced skin carcinoma. Drug Des Devel Ther. 2015;9:2793-800.

13. Activity of Aristolochia indica in alloxan-induced diabetic mice with a reference to in vitro antioxidant activity. J Med Plant Res. 2012;6:1219-23.

14. Snyder LR. Classification of the solvent properties of common liquids. $J$ Chromatogr. 1974;92:223-30.

15. Owen RW, Mier W, Giacosa A, Hull WE, Spiegelhalder B, Bartsch H. Phenolic compounds and squalene in olive oils: the concentration and antioxidant potential of total phenols, simple phenols, secoiridoids, lignansand squalene. Food Chem Toxicol. 2000;38:647-59.

16. Murakoshi M, Nishino $H$, Tokuda $H$, Iwashima A, Okuzumi J, Kitano $\mathrm{H}$, et al. Inhibition by squalene of the tumor-promoting activity of 12-O-tetradecanoylphorbol-13- acetate in mouse-skin carcinogenesis. Int J Cancer. 1992;52:950-2.

17. Banyai W, Sangthong R, Karaket N, Inthima P, Mii M, Supaibulwatana K. Overproduction of artemisinin in tetraploid Artemisia annua L. Plant Biotechnol. 2010;27(5):427-33

18. Koizumi Y, Tomoda H, Kumagai A, Zhou X, Koyota S, SugiyamaT. Simaomicin $\alpha$, a polycyclic xanthone, induces $\mathrm{G} 1$ arrest with suppression of retinoblastoma protein phosphorylation. Cancer Science. 2009;100:322-6.

19. Zhang C, Yu G, Shen Y. The naturally occurring xanthone $\alpha$-mangostin induces ROS-mediated cytotoxicity in non-small scale lung cancer cells. Saudi J Biol Sci. 2017;25(6):1090-5.

20. Batova1 A, Altomare D, Chantarasriwong O, Ohlsen KL, Creek KE, Lin YC, et al. The synthetic caged Garcinia xanthone cluvenone induces cell stress and apoptosis and has immune modulatory activity. Mol Cancer Ther. 2010;9(1):2869-78

21. Thonga NM, Quangb DT, Buic NHT, Daod DQ, Namc PC. Antioxidant properties of xanthones extracted from the pericarp of Garcinia mangostana (Mangosteen): A theoretical study. Chem Phys Lett. 2015;625:30-5.

22. Mahamodo S, Rivière $C$, Neut $C$, Abedini $A$, Ranarivelo $H$, Duhal $N$, et al. Antimicrobial prenylated benzoylphloroglucinol derivatives and xanthones from the leaves of Garcinia goudotiana. Phytochemistry. 2014;102:162-8.

23. Guinebretie're MH, Broussolle V, Nguyen-The C. Enterotoxigenic Profiles of Food-Poisoning and Food-Borne Bacillus cereus Strains. J Clin Microbiol. 2002;40(8):3053-6.

24. Radha KK, James F, Mohan A. Isolation and characterization of n-hexadecanoic acid from Canthium parviflorum leaves. J Chem Pharm Res. 2016;8(8): 614-7.

25. Yasunaka K, Abeb F, Nagayamaa A, Okabeb H, Lozada-P'erezc L, L'opez Villafrancod $E$, et al. Antibacterial activity of crude extracts from Mexican medicinal plants and purified coumarins and xanthones. J Ethnopharmaco. 2005;97:293-9

26. Sule A, Ahmed QU, Samah OA, Omar MN. Bacteriostatic and bactericidal activities of Andrographis paniculata extracts on skin disease causing pathogenic bacteria. J Med Plant Res. 2011;5(1):7-14.

27. Zaidan MRS, Noor RA, Badrul AR, Adlin A, Norazah A, Zakiah I. In vitro screening of five local medicinal plants for antibacterial activity using disc diffusion method. Trop Biomed. 2005;22(2):165-70.

28. Inthima P, Otani M, Hirano T, Hayashi Y, Abe T, Nakano M, et al. Mutagenic effects of heavy-ion beam irradiation on in vitro nodal segments of Artemisia annua L. Plant Cell Tiss Organ Cult. 2014;119:131-9. 


\section{GRAPHICAL ABSTRACT}

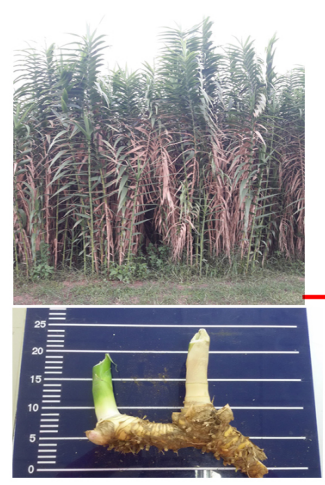

Arundo donax L. (Rhizome)
Phytochemical analysis by GC-MS

\section{ABOUT AUTHORS}

- Kanoktip Pansuksan; PhD (Biotechnology): Presently work at Chulabhorn International College of Medicine, Thammasat University (Rangsit campus), THAILAND. The researches are in the fields of plant improvement by biotechnology methods and herbal medicines with diuretic property.

- Sophida Sukprasert; PhD (Biochemistry): Presently work at Chulabhorn International College of Medicine, Thammasat University (Rangsit campus), THAILAND. Her research focused on herbal medicines which possess antidote and anti-diabetic properties. Furthermore, immunomodulatory effect of any substance has been also investigated in vivo and clinical studies.

- Netiya Karaket; PhD (Biotechnology): Presently work at School of Interdisciplinary Studies, Mahidol University (Kanchanaburi Campus), THAILAND. The research is in the field of phytochemical compound analysis using various techniques such as chromatography and Nuclear magnetic resonance techniques.

Cite this article: Pansuksan K, Sukprasert S, Karaket N. Phytochemical Compounds in Arundo donax L. Rhizome and Antimicrobial Activities. Pharmacog J. 2020;12(2):287-92. 